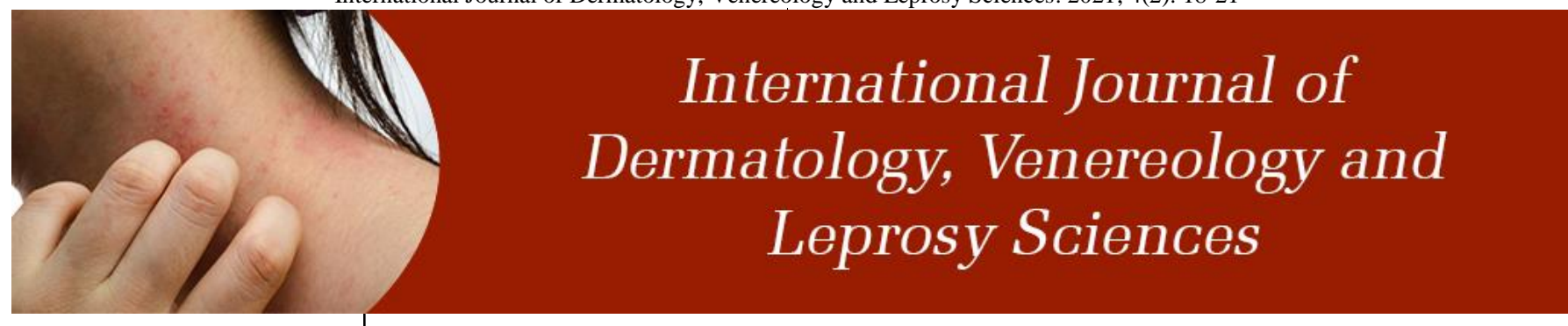

E-ISSN: 2664-942X

P-ISSN: 2664-9411

www.dermatologypaper.com

Derma 2021; 4(2): 18-21

Received: 07-04-2021

Accepted: 09-06-2021

\section{BM Monisha}

Assistant Professor, Skin and STD Department, Vinayaka Mission's Kirupananda Variyar Medical College \& Hospital, Salem, Tamil Nadu, India

\section{S Vinoth Kumar}

Associate Professor,

Department of Radiology,

Vinayaka Mission's

Kirupananda Variyar Medical

College \& Hospital, Salem,

Tamil Nadu, India

\section{Dr. Keerthana $S$}

First Year PG, Skin and STD

Department, Vinayaka

Mission's Kirupananda

Variyar Medical College \&

Hospital, Salem, Tamil Nadu,

India
Corresponding Author:

\section{BM Monisha}

Assistant Professor, Skin and STD Department, Vinayaka Mission's Kirupananda Variyar Medical College \& Hospital, Salem, Tamil Nadu, India

\section{A study of wood's lamp findings in melasma}

\author{
BM Monisha, S Vinoth Kumar and Dr. Keerthana S
}

DOI: https://doi.org/10.33545/26649411.2021.v4.i2a.85

\begin{abstract}
Introduction: Melasma is main cause of facial hyperchromia and has a significant psychosocial impact. Wood's lamp has been a useful device to estimate the depth of melanin determined by lightinduced fluorescence. A dermoscope enables a clear visualization of pigments distribution, and the color variation of melanin will depend on its location within the skin

Methods: A cross-sectional observational study was conducted at the outpatient section of the Department of Dermatology of a tertiary care teaching hospital. A total of 120 patients were enrolled for a duration of 1 year. Patients diagnosed to have melasma on clinical grounds were enrolled after considering various inclusion and exclusion criteria.

Result: On clinical examination, 47 patients had centrofacial distribution and 73 had malar distribution of melisma. On Wood's lamp 51 patients showed complete enhancement hence classified as epidermal, 63 patients had no enhancement hence classified as dermal and 6 patients showed few areas of enhancement and hence classified as mixed melasma. On dermoscopy, 48 patients showed regular pigment network with a brownish homogeneous pigmentation hence classified as epidermal, 61 patients showed Irregular network with bluish grey pigmentation hence classified as dermal and 11 patients showed features of both epidermal and dermal and hence classified as mixed melasma.

Conclusion: In the analysis of correlation between Dermoscopy and Wood's lamp in classification of Melasma, the results showed substantial discordance between the methods. Based on the principles of Dermoscopic examination, this method applicable, more appropriate and helpful for routine diagnosis, assessment and monitoring of patients with melasma.
\end{abstract}

Keywords: melasma, wood's lamp, dermoscopic examination

\section{Introduction}

Melasma is an important disease characterized by acquired hyperpigmentation and is the main cause of facial hyperpigmentation. It is a chronic condition characterized by symmetrical and asymptomatic brownish spots in sun-exposed areas. This frequent condition has a considerable influence on the quality of life of affected patients ${ }^{[1]}$. Females are predominantly affected by melasma (90\%), which occurs mainly during the reproductive period. Is more prevalent in Asians and individuals of Hispanic origin, as well as in patients with skin prototypes III to V according to Fitzpatrick's classification, especially in residents of areas under intense ultraviolet radiation ${ }^{[2]}$. Classification of melasma has significance for both prognosis and the search for appropriate therapy, since the proposed treatments are largely inadequate. This refractoriness associated with common relapses and the typical predilection for the face is a cause of dissatisfaction and significant psicossocial impact ${ }^{[3]}$.

Wood's lamp also called as black light, emits long wave UV radiation. The wood's filter is made up of barium silicate with $9 \%$ nickel oxide ${ }^{[4]}$. In melasma wood's lamp will be useful in identifying the melanin accumulation in layers of skin by light induced fluorescence. This is the most widely used method for classification of melisma ${ }^{[5]}$. Usually melasma is diagnosed clinically but with this additional tool it helps in identifying the depth of pigment. Thus, its classification aids in prognosis and helpful in therapeutic outcome.

Dermatosis is clinically classified by the lesions topographical disposition and the distribution of melanin in the skin layers through histopathological examinations and Wood's lamp. There are basically three patterns considered on clinical examination: Centro facial, malar, and mandibular. The first is the most common and involves the malar, frontal, mentoniane, supralabial, and nasal. The second includes the malar and nasal areas, and the mandibular pattern affects the respective region. Although less common, other sites may be involved, as the neck and arms, forming an extra facial melasma which may be associated with any of the other patterns ${ }^{[6]}$. 


\section{Materials and Methods}

A cross-sectional observational study was conducted at the outpatient section of the Department of Dermatology of a tertiary care teaching hospital. The study was conducted after the approval of the Institutional Ethics Committee. The study was conducted according to good clinical practice (GCP) guidelines. A total of 120 patients were enrolled for a duration of 1 year. Patients diagnosed to have melasma on clinical grounds were enrolled after considering various inclusion and exclusion criteria. After enrolment, a detailed demographic profile and clinical history was obtained from each of the study participants. A well-trained expert performed a thorough cutaneous examination.

Melasma was classified clinically on the basis of the pattern of distribution. Clinical photographs were obtained using a Nikon digital single lens reflex camera. The severity of melasma was assessed with the help of validated scoring system-Melasma Area Severity Index. All study participants were examined by an expert using an artificial Wood's lamp to assess the depth of pigmentation. The patients were classified to have epidermal, dermal, and mixed type of melasma. A dermatoscopic examination of melasma was performed using Denolite AD 4113 dermoscope (under 90x magnification and no contact fluid) with an image capturing software. All clinical, Wood's lamp, and dermatoscopic images were saved in jpeg (Joint Photograph Expert Group) format. The dermatoscopic classification of melasma was done on the basis of definitive pigmentary pattern ${ }^{[1]}$. According to dermatoscopy, melasma presents in the following patterns: epidermal melasma presents as regular pigment network with a brownish homogenous pigmentation, dermal melasma presents as grayish brown or grayish black pigmentation with irregular pigment network and mixed type shows the features of both epidermal and dermal types.

\section{Statistical Analysis}

Data will be entered in MS EXCEL and assessed with SPSS latest version. Variables were summarized and entered in excel chart. The possible associations with demographic variables were analysed using Chi-square method. $\mathrm{P}$ value less than 0.05 will be considered significant.

\section{Result}

Total of 120 patients were included in the study, of which 34 were male and 86 were female. Their ages ranged between 20 and more than 50 years, with mean age of 32.43 years as shown in Table 1 and 2 .

Table 1: Distribution of gender

\begin{tabular}{|c|c|c|}
\hline Gender & No. of patients & Percentage \\
\hline Male & 34 & 28.3 \\
\hline Female & 86 & 71.6 \\
\hline Total & 120 & 100 \\
\hline
\end{tabular}

Table 2: Distribution of Age

\begin{tabular}{|c|c|c|}
\hline & No. of patients & Percentage \\
\hline $20-30$ & 29 & 24.1 \\
\hline $31-40$ & 53 & 44.1 \\
\hline $41-50$ & 27 & 22.5 \\
\hline$>50$ & 11 & 9.1 \\
\hline Total & 120 & 100 \\
\hline
\end{tabular}

Table 3: MASI score grading

\begin{tabular}{|c|c|c|}
\hline MASI & No. of patients & Percentage \\
\hline $0-5$ & 27 & 22.5 \\
\hline $6-10$ & 62 & 51.6 \\
\hline$>10$ & 31 & 25.8 \\
\hline Total & 120 & 100 \\
\hline
\end{tabular}

Table 4: Clinical diagnosis:

\begin{tabular}{|c|c|c|}
\hline & Frequency & Total \\
\hline Malar & 73 & 60.8 \\
\hline Centrofacial & 47 & 39.2 \\
\hline Total & 120 & 100 \\
\hline
\end{tabular}

In table 4 , on clinical examination, 47 patients had centrofacial distribution and 73 had malar distribution of melisma.

Table 5: Wood's lamp diagnosis

\begin{tabular}{|c|c|c|}
\hline Wood's lamp feature & Frequency & Percentage \\
\hline Enhancement seen & 51 & 42.5 \\
\hline No enhancement & 63 & 52.5 \\
\hline Few areas enhanced & 6 & 5 \\
\hline Total & 120 & 100 \\
\hline
\end{tabular}

In our study, on Wood's lamp 51 patients showed complete enhancement hence classified as epidermal, 63 patients had no enhancement hence classified as dermal and 6 patients showed few areas of enhancement and hence classified as mixed melasma.

Table 6: Dermoscopy diagnosis

\begin{tabular}{|c|c|c|}
\hline Dermoscopic features & Frequency & Percentage \\
\hline Regular network & 48 & 40.0 \\
\hline Irregular network + bluish gray pigment & 61 & 50.8 \\
\hline Both & 11 & 9.1 \\
\hline Total & 120 & 100 \\
\hline
\end{tabular}

In our study on dermoscopy, 48 patients showed regular pigment network with a brownish homogeneous pigmentation hence classified as epidermal, 61 patients showed Irregular network with bluish grey pigmentation hence classified as dermal and 11 patients showed features of both epidermal and dermal and hence classified as mixed melasma.

\section{Discussion}

Melasma is an acquired hypermelanosis of sun-exposed areas. It presents as symmetrical hyperpigmented macules and patches, which can be confluent or punctate. The cheeks, the upper lip, the chin, and the forehead are the most common locations, but it can occasionally occur in other sun-exposed locations. Though commonly seen in women, it can also occur in men. Multiple factors have been postulated to involve in the aetiology and pathogenesis of melasma including pregnancy, oral contraceptives, genetics, sun exposure, cosmetics and race ${ }^{[7]}$.

Melasma predominantly affects Fitzpatrick skin phototypes III and $\mathrm{V}$ and often lasts for many years after pregnancy ${ }^{[8]}$. The incidence of melasma in pregnant ladies with white skin is reported to be more than $50 \%$ of the cases. However, in India it was found to be nearly $10 \%{ }^{[9]}$. 
The hyperpigmented patches may range from single to multiple, usually symmetrical on the face and occasionally $\mathrm{V}$-neck area. According to the distribution of lesions, three clinical patterns of melasma are recognized. The centrofacial pattern is the second most common pattern and involves the forehead, cheeks, upper lip, nose, and chin. The malar pattern involves the cheeks and nose. The mandibular pattern involves the ramus of the mandible ${ }^{[10]}$.

Through Wood's lamp examination, the following types are described: epidermal-there is a colour accentuation as the light is absorbed by the excess of melanin in the basal or suprabasal regions; dermal-such accentuation is not noticeable; mixed-as the deposit of melanin occurs in both dermis and epidermis, increased staining is seen only in a few sites. Some even describe a fourth type that would be unnoticed in Wood's light, because it affects individuals of phototype V and VI. It is so named because the melanin in these patients is abundant and most of the light is absorbed by this pigment. Only a small amount returns to the eyes, and the skin appears dark as a whole ${ }^{[11]}$.

A traditional Wood lamp is a low-output mercury arc covered by a Wood filter (barium silicate and 9\% nickel oxide), and emits wavelength 320-450nm (peak $365 \mathrm{~nm}$ ). This was invented in 1903 by a Baltimore physicist; Robert W. Wood. Wood's lamp can be used to determine the depth of melanin in the skin. The variations in epidermal pigmentation become more apparent under Wood's light. For dermal pigmentation, this contrast is less pronounced. Based on Wood's light findings, Sanchez et al. classified melasma into four subtypes: epidermal, dermal, mixed and Wood's light inapparent ${ }^{[12]}$. While a Wood lamp examination was previously thought to accurately predict epidermal versus dermal pigment deposition, recent studies have shown that dermal melanin deposition is common and may be under-recognized ${ }^{[13]}$.

Wood's lamp is the most widely used method of melasma classification. A study conducted by Ponzio et al. (1993) to assess the instrument validity to identify the pattern of melasma, aimed to determine the cases correctly classified in 61 patients, compared with the histopathological examination. The study showed low levels of sensitivity, specificity and accuracy of the examination under Wood's lamp in the three pathological types of melasma. The results obtained in this sample concluded that "classification of melasma by examining the skin under Wood's lamp has a low proportion of correct answers, since it proved to be moderately sensitive but with low specificity, resulting in accuracy of $46 \%$, below the expectation" ${ }^{[14]}$.

Ultraviolet light from Wood's lamp penetrates predominantly in the stratum corneum and epidermis where melanin is distributed. The pigment depth will determine the fluorescence. The skin regions presenting an increase in epidermal melanin concentration will enhance their colour and become darker, in contrast to the normal surrounding skin. In contrast, the areas with decreased melanin concentrations will appear clearer and brighter. Thus, variations in epidermal pigmentation are more visible under a Wood's lamp, whereas dermal changes are much less evident or absent under the lamp compared to visible light. Less UV light reaches the dermis and this contributes much less to the fluorescence that returns to the eyes, i.e., dermal melanin does not affect the amount of light observed. Contrast between the affected and unaffected skin is considerably decreased or even unapparent compared to visible light ${ }^{[15]}$. Therefore, an established disadvantage is the fact that the technique will not be useful in individuals of skin type V and VI due to optical factors. Moreover, collagen and vascular changes, use of topical drugs and sunscreen can affect the test, resulting in unreliable results. [16] There are reports that the proposed therapies are effective mainly in the epidermal type, without good results for the dermal component ${ }^{[17]}$.

Dermatoscope is a non-invasive, diagnostic tool, also known as dermoscope, skin surface microscope, epiluminescence microscope and episcope. It magnifies subtle clinical surface features of skin lesions and also unveils some subsurface skin structures not normally visible even with a magnifying lens ${ }^{[18]}$.

Dermoscopy of melasma shows very characteristic changes. The colour intensity of melanin and the regularity of the pigment network reveal the density and location of melanin. It presents dark brown colour and well-defined network when located in the stratum corneum; shades of light brown and irregularity of the network when located in the lower layers of the epidermis sparing the follicles and sweat gland openings producing exaggerated pseudonet work pattern with concave borders called the 'jelly sign' and blue or bluish gray colour when located in the dermis. It is possible to see the vascular component, which is present in a large number of patients ${ }^{[19]}$.

\section{Conclusion}

Dermoscopic examination helps in observing the pigment components, as well as their position on the skin layers. In the analysis of correlation between Dermoscopy and Wood's lamp in classification of Melasma, the results showed substantial discordance between the methods. Based on the principles of Dermoscopic examination, this method applicable, more appropriate and helpful for routine diagnosis, assessment and monitoring of patients with melasma. Dermoscopy also allowed the observation of significant vascular component in many patients, which may be relevant in terms of future prospects for pathogenesis and therapeutic considerations.

\section{References}

1. Wang YJ, Chang CC. Epidermal grafting for leukoderma resulting from 1064-nm quality-switched neodymium-doped yttrium aluminium garnet laser toning. Int Wound J 2018;15(6):1045-1048.

2. Shakeeb N, Noor SM, Ullah G, Paracha MM. Efficacy of Intense Pulse Light Therapy and Tripple Combination Cream Versus Intense Pulse Light Therapy and Tripple Combination Cream Alone in Epidermal Melasma Treatment. J Coll Physicians Surg Pak 2018;28(1):13-16.

3. Handa S, De D, Khullar G, Radotra BD, Sachdeva N. The clinicoaetiological, hormonal and histopathological characteristics of melasma in men. Clin Exp Dermatol 2018;43(1):36-41.

4. Sun R, Chen H, Zhu W, Lian S. Wood's lamp image of porokeratosis. Photodermatol Photoimmunol Photomed 2017;33(2):114-116.

5. Rojas Mora E, Freites Martínez A, Hernández-Núñez A, Borbujo Martínez J. Trichomycosis axillaris: Clinical, Wood lamp, and dermoscopic diagnostic images. Actas Dermosifiliogr 2017;108(3):264-266.

6. Pinto M, Hundi GK, Bhat RM, Bala NK, Dandekeri S, 
Martis J, et al. Clinical and epidemiological features of coryneform skin infections at a tertiary hospital. Indian Dermatol Online J 2016;7(3):168-73.

7. Cogulet A, Blanchet P, Landry V. Wood degradation under UV irradiation: A lignin characterization. J Photochem Photobiol B 2016;158:184-91

8. Osmancevic A, Demeke T, Gillstedt M, Angesjö E, Sinclair H, Abd El-Gawad G, et al. Vitamin D treatment in Somali women living in Sweden - Two randomized, placebo-controlled studies. Clin Endocrinol (Oxf) 2016;85(4):535-43.

9. Achar A, Rathi SK. Melasma: A clinicoepidemiological study of 312 cases. Indian J Dermatol 2017;56:380-2.

10. Hee Young Kang. Etiological Factors and Triggering Factors. Dalam: Melasma a monograph, Rashmi sarkar, editors. Edisi ke 1. New Delhi: Jaypee; 2015. Hal 4-5 [10] Bagherani N, Gianfaldoni S, Smoller B. An overview of melasma. Pigmentary disorders 2015;2(10):1-18.

11. Simmons BJ, Griffith RD, Bray FN, et al. Exogenous Ochronosis: A Comprehensive Reviewof the Diagnosis, Epidemiology, Causes, and Treatments. Am J Clin Dermatol 2015;16:205-212.

12. Jagannathan M, Sadagopan K, Ekkarakudy J, Anandan H. Clinicoepidemiological Study of Patients with Melasma in a Tertiary Care Hospital - A Prospective Study. International Journal of Scientific Study 2017;4:117-20.

13. Chlebus E, Chlebus M. Factors affecting the course and severity of adult acne. Observational cohort study. J Dermatolog Treat 2017;28:737-44.

14. Uysal G, Sahin Y, Unluhizarci K, Ferahbas A, Uludag $\mathrm{SZ}$, Aygen E, et al. Is acne a sign of androgen excess disorder or not? Eur J Obstet Gynecol Reprodu Biol. 2017;211:21-5.

15. Shrestha S. Correlation of hormonal profile and lipid levels with female adult acne in a Tertiary care center of Nepal. J Nepal Health Res Counc 2018;16:222-7.

16. Sardana K, Singh C, Narang I, Bansal S, Garg VK. The role of antiMullerian hormone in the hormonal workup of women with persistent acne. J Cosmet Dermatol 2016;15:343-9.

17. Kaminsky A, Florez-White M, Bagatin E, Arias MI. Large prospective study on adult acne in Latin America and the Iberian peninsula: Risk factors, demographics, and clinical characteristics. Int $J$ Dermatol 2019;58:1277-82.

18. Di Landro A, Cazzaniga S, Cusano F, Bonci A, Carla C, Musumeci ML, et al. Adult female acne and associated risk factors: Results of a multicenter casecontrol study in Italy. J Am Acad Dermatol 2016;75:1134-41.e1.

19. George RM, Sridharan R. Factors aggravating or precipitating acne in Indian adults: A hospital-based study of 110 cases. Indian J Dermatol 2018;63:328-31. 